JOURNAL OF

SYNCHROTRON

RADIATION

ISSN 1600-5775

Received 7 May 2021

Accepted 20 August 2021

Edited by S. Svensson, Uppsala University, Sweden

Keywords: X-ray generation; plasma X-ray sources; OPCPA lasers; compact $\mathrm{X}$-ray sources.

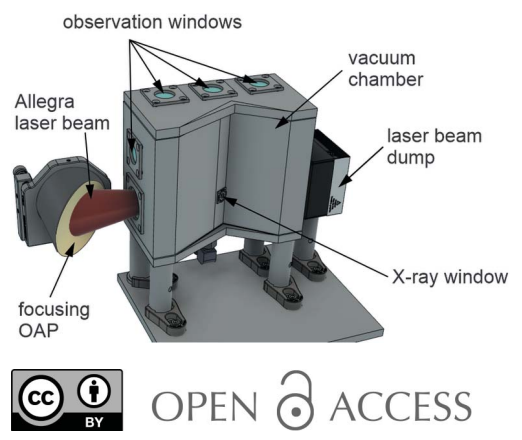

\section{First experiments with a water-jet plasma X-ray source driven by the novel high-power-high- repetition rate L1 Allegra laser at ELI Beamlines}

\author{
Anna Zymaková, ${ }^{a *}$ Martin Albrecht, ${ }^{\mathrm{b}}$ Roman Antipenkov, ${ }^{\mathrm{c}}$ Alexandr Špaček, \\ Stefan Karatodorov, ${ }^{b}$ Ondřej Hort, ${ }^{b}$ Jakob Andreasson ${ }^{a}$ and Jens Uhlig ${ }^{d}$
}

\footnotetext{
astructural Dynamics, ELI Beamlines, Za Radnici 835, Dolni Brezany 25241, Czech Republic, bX-ray sources, ELI Beamlines, Za Radnici 835, Dolni Brezany 25241, Czech Republic, ' L1 Allegra Laser, ELI Beamlines, Za Radnici 835, Dolni Brezany 25241, Czech Republic, and dDivision of Chemical Physics, Lund University, Box 117, Lund 22100, Sweden. *Correspondence e-mail: anna.zymakova@eli-beams.eu
}

ELI Beamlines is a rapidly progressing pillar of the pan-European Extreme Light Infrastructure (ELI) project focusing on the development and deployment of science driven by high-power lasers for user operations. This work reports the results of a commissioning run of a water-jet plasma X-ray source driven by the L1 Allegra laser, outlining the current capabilities and future potential of the system. The L1 Allegra is one of the lasers developed in-house at ELI Beamlines, designed to be able to reach a pulse energy of $100 \mathrm{~mJ}$ at a $1 \mathrm{kHz}$ repetition rate with excellent beam properties. The water-jet plasma X-ray source driven by this laser opens opportunities for new pump-probe experiments with sub-picosecond temporal resolution and inherent synchronization between pump and probe pulses.

\section{Introduction}

The quest to study light-mediated processes has driven the development of facilities capable of producing ultrashort pulses of X-ray radiation (Ponseca et al., 2017; Kranz \& Wächtler, 2021; Chergui \& Collet, 2017; Milne et al., 2014). Laser-driven sources can reliably produce such radiation in a wide range of energies and combine the benefits of a compact setup with a high level of integratibility in a multi-purpose laboratory at affordable cost (in comparison with other largescale facilities). For ultrafast pump-probe experiments, the all-optical approach of beam generation offers excellent synchronization between two or more beams. Such a facility has the potential for e.g. advanced shaped pump pulses (Assion et al., 1998; Brüggemann et al., 2006) and the intriguing capability for probes in different wavelength ranges, e.g. visible, terahertz and $\mathrm{X}$-ray, using the same pump. The source described here is installed within a modular X-ray spectroscopy end-station, potentially motivating the use of multiple complementary methods for a comprehensive study [see De Roche et al. (2003), Naumova et al. (2018), Dicke et al. (2018), Kunnus et al. (2020) and Kjaer et al. (2019) for examples].

Laser-driven plasma X-ray sources (PXS) (Mallozzi et al., 1974; Turcu \& Dance, 1999; Benesch et al., 2004) are based on focusing a laser with ultrashort (sub-100 fs) pulse durations and a peak intensity of $10^{15}-10^{17} \mathrm{~W} \mathrm{~cm}^{-2}$ onto a renewable target (Fullagar, Harbst et al., 2007; Korn et al., 2002; Zamponi et al., 2009; Uhlig et al., 2013; Weisshaupt et al., 2014; Afshari et al., 2020). This results in ionization of surface atoms and plasma generation at the steep density gradient at the interface (Fullagar, Harbst et al., 2007; Chen et al., 2001; Brunel, 
1987; Korn et al., 2002; Uhlig et al., 2011; Gibbon, 2005; Mulser \& Bauer, 2010; Kruer, 2003; Uhlig et al., 2013). Electrons in the plasma are subsequently accelerated by the electric field of the driving laser and finally interact with the target atoms, producing characteristic line emission (intense spectral peaks) and isotropic Bremsstrahlung radiation (continuous broadband background spectrum) (Brunel, 1987). The duration of the generated Bremsstrahlung X-ray pulse in the hard X-ray range $(>4 \mathrm{keV})$ is mainly influenced by the duration of the laser heating (pulse duration of the driving laser) and the interaction path length $(\sim 4-10 \mu \mathrm{m})$, and is typically $>400 \mathrm{fs}$ (Afshari et al., 2020; Fullagar, Harbst et al., 2007; Bargheer et al., 2006; Pfeifer et al., 2006). The complex processes in the interaction region and the wide range of applications led the research towards the development of many different target types and pulse conditions over the past two decades (Gibbon, 2005; Uhlig, 2011; Martynow et al., 2019; Eliezer \& Kunioki, 2019; Brauckmann, 2017; Macchi, 2013; Miaja-Avila et al., 2016; O’Neil et al., 2017; Koç et al., 2021; Gibbon, 2005; Mulser \& Bauer, 2010; Kruer, 2003).

The conditions and operational demands that make this facility unique and challenging are a high laser pulse energy (up to $100 \mathrm{~mJ}$ ) and a high repetition rate $(1 \mathrm{kHz}$ ), representing $100 \mathrm{~W}$ average power, combined with the demands of stability and flexibility required for a user facility that can be operated continuously over long periods of time.

At the end of 2019, a water-jet PXS was delivered and installed on the X-ray spectroscopy end-station at ELI Beamlines as a complement to the metal target X-ray sources currently being under development. The choice of a low- $Z$ target combines the absence of characteristic lines (wide usable spectral range) with simplicity of experimental use, including nontoxicity of the target at room temperature, stability of operation, availability, and ease of debris handling (Martynenko et al., 2021; Miaja-Avila et al., 2015; Uhlig et al., 2015; Uhlig, 2011). The compact experimental chamber with total dimensions $100 \mathrm{~mm} \times 180 \mathrm{~mm} \times 162 \mathrm{~mm}(\mathrm{~W} \times \mathrm{L} \times \mathrm{H})$ makes the water-jet PXS an attractive candidate for the tightly packed multi-purpose X-ray spectroscopy end-station. Here we describe the commissioning run of this water-jet PXS driven by the $1 \mathrm{kHz}$ L1 Allegra laser developed in-house, and assess its current feasibility for time-resolved experiments. The L1 Allegra laser utilizes the optical parametric chirpedpulse amplification (OPCPA) technique that combines high power with exceptional temporal contrast with the ability to shape the temporal structure (Batysta et al., 2016) and optimize the dispersion of the laser beam according to the needs of a particular experiment.

The initial experimental run reported here was conducted in September 2020 and represents the first demonstration of hard $\mathrm{X}$-ray generation with the L1 Allegra laser. The run was performed at a reduced laser power of $10-12 \mathrm{~mJ}$ per pulse under modal and chirp conditions that were non-optimal for the source. Neither position tracking nor alignment pinholes were available/used, although these measures are/will be implemented for future user operation.

PXS sources have shown a strong dependence on the electron temperature and integral flux of the driving power and on the precise interaction conditions (Miaja-Avila et al., 2015; Fullagar, Harbst et al., 2007). Based on these results, we will carefully estimate the perspective of the expected source $\mathrm{X}$-ray flux and experimental conditions as the L1 Allegra laser approaches its design pulse energy of $100 \mathrm{~mJ}$.

\section{Experimental}

The L1 Allegra laser system is based on a broadband OPCPA, pumped by picosecond Yb:YAG thin-disc lasers. After amplification, the broadband pulses are compressed to $<15$ fs (with the transorm limit around $12 \mathrm{fs}$ ) using a chirped mirror compressor. The system operates at a $1 \mathrm{kHz}$ repetition rate with the central wavelength around $830 \mathrm{~nm}$. At the time of writing, the L1 Allegra laser is in a ramp-up programme to reach $50 \mathrm{~mJ}$ for general user operations and has a maximum (design) value of $100 \mathrm{~mJ}$. The laser is designed to be operated at multiple power levels, switching between a safe alignment mode and the high-power operation. For the present experiments, the system was used at a pulse energy level in the range

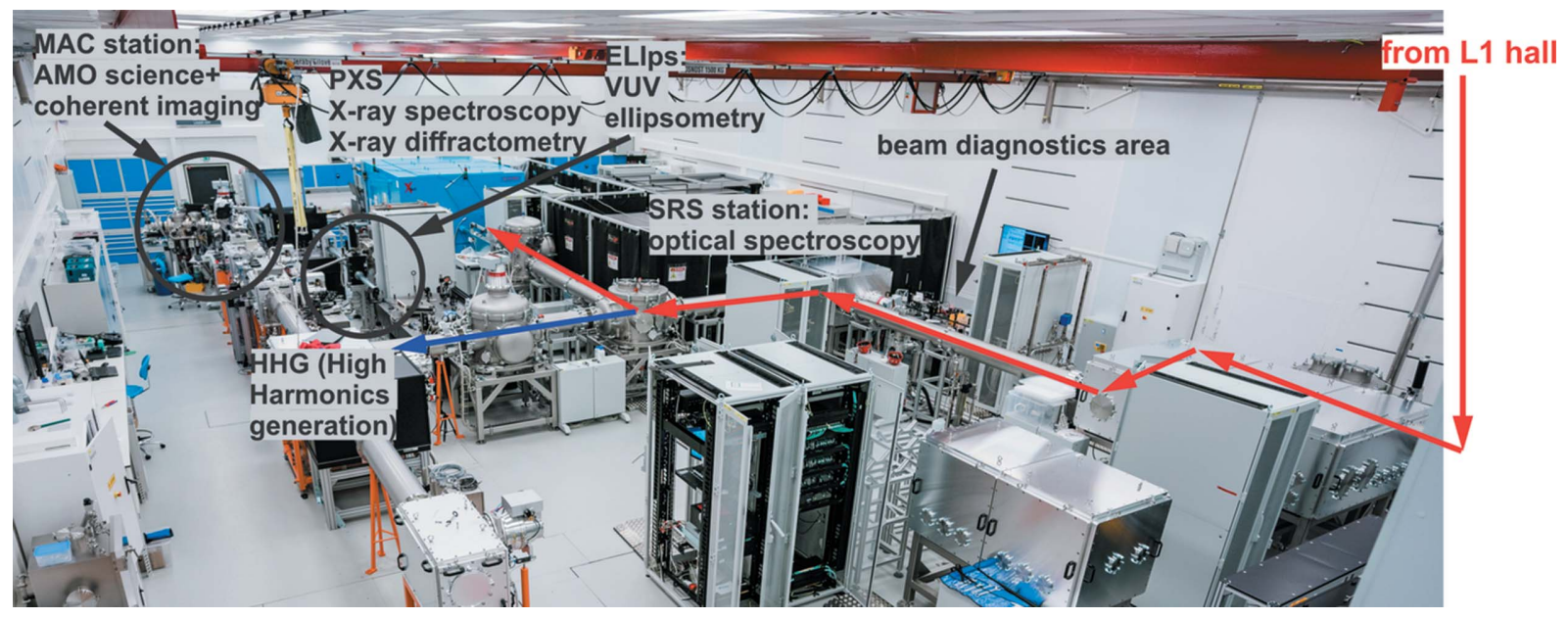

Figure 1

General layout of E1 experimental hall and L1 Allegra laser beam transport. Red arrows show Allegra beam transport to the water-jet PXS. 
of $10-12 \mathrm{~mJ}$ and intensity contrast of $10^{-9}$ on the picosecond scale (Antipenkov et al., 2019). In the large ELI Beamlines facility, the laser is located in a different room on a different floor, with an in-vacuum beam path of $\sim 40 \mathrm{~m}$ from the last mirror of the L1 Allegra injector to the experimental station. The beam transport is done in high vacuum $\left(10^{-6} \mathrm{mbar}\right.$; 1 bar $=100000 \mathrm{~Pa}$ ) on four-inch optics.

A general view of the beam transport and experimental areas in the E1 experimental hall is shown in Fig. 1. The L1 Allegra laser is sent from the L1 hall, located above E1, and can be directed to one of two types of secondary sources - an HHG source for XUV radiation (Hort et al., 2019, 2020) or plasma X-ray sources (Nejdl et al., 2019). The HHG source serves two stations for XUV science: 'MAC' for atomic, molecular and optical science and coherent diffractive imaging (Klimesová et al., 2021), and 'ELIps' for XUV materials science applications (Espinoza et al., 2020). Complementary methods for ultrafast optical spectroscopy are also available (using support lasers): transient optical absorption (Naumova et al., 2018), stimulated Raman scattering (Andrikopoulos et al. 2020), time-resolved spectroscopic ellipsometry (Richter $e t$ al., 2021) and IR (1D and 2D) spectroscopy.

For the water-jet PXS, inside a small safety hutch designated for X-ray experiments, the laser beam is coupled out of the vacuum transport through a CF100 window. The power and polarization of the driving laser are adjusted by a half-wave plate and two Brewster windows in an Altechna laser attenuator, ensuring horizontally polarized light at the interaction region, and finally focused by a three-inch $90^{\circ}$ off-axis parabolic (OAP) mirror with $15 \mathrm{~cm}$ focal length. Most of the group velocity dispersion introduced through all optical elements in the beam path is then compensated through optimization of the supercontinuum created by the focused beam in air. The effects of pulse compression and other laser parameters have been discussed previously (Fullagar et al., 2008; Uhlig, 2011).

The water-jet PXS chamber is based on existing design iterations (Fullagar, Harbst et al., 2007; Uhlig et al., 2013; Uhlig, 2011) and was adapted for use with the high-power beam from the L1 Allegra laser (Zymaková et al., 2020). The combination of the high power and high repetition rate of the laser can result in damage to the optical components, strong cooling of the chamber due to increased evaporation can lead to the formation of ice, and the high-repetition rapid expansion of gas/water created by the focused laser beam increases the debris load. The upgraded design (see Fig. 2) includes increased optical apertures for damage mitigation at the antireflection coated windows.

An external beam dump located on the opposite side of the laser entrance window terminates the high-pulse-energy beam of the L1 Allegra laser and is thermally coupled to the water jet catcher/outlet. This transfers a part of the laser energy to the chamber, effectively preventing ice formation, reducing water condensation on the windows, and supporting dissipation of $100 \mathrm{~W}$ average power ultimately expected from the laser. A flexible and improved debris handling system confines the mist with dedicated flow channels, and a tight design allows outcoupling of the X-ray radiation close to the source $(<1.2 \mathrm{~mm})$ without exposing the window material to potential reflections of the laser. The vacuum chamber contains strategically placed windows to ease alignment and allow inspection of the target jet and the laser-jet interaction zone. Two cameras with magnifying optics are installed for observation of the laser focus and interaction region from two perpendicular directions. Under usual operation conditions, the optical elements before the chamber consist of a modular beamsplitter and an OAP mirror that is initially optimized and then kept static. The X-ray source chamber including the water jet is remotely positioned relative to the laser focus, controlling the interaction region.

The X-ray source and all X-ray optical elements, like an X-ray polycapillary lens (Zymaková et al., 2020), are mounted on a common base plate and move in conjunction with the chamber and the rigidly mounted water jet, maintaining their relative alignment. The sample section and the focusing lens of the pump beam are either mounted on the same baseplate or independently, depending on the experiment. The target is a cylindrical $100-300 \mu \mathrm{m}$ thick water jet formed by a highperformance liquid chromatography (HLPC) nozzle at a typical speed of $\sim 6 \mathrm{~m} \mathrm{~s}^{-1}$ driven by a 1-2 bar pressure difference between a pressurized reservoir and the evacuated experimental chamber. The setup uses two identical reservoirs each lasting for $10-12 \mathrm{~h}$ of operation, the current facilitylimited working time. The flow design allows for fast reservoir switching and near-continuous operation.

The interaction region is typically located on the jet $3 \mathrm{~mm}$ below the opening of the HLPC nozzle, ensuring a complete replacement of the interaction/source region surface for each pulse of the driving laser and a very smooth surface. The water is degassed in vacuum and pressurized with industry-quality helium. These measures prevent instability of the jet as it enters the target chamber (Otendal et al., 2005), which is verified by direct inspection with a microscope and observation of the laser beam reflected from the jet surface.

The water-jet PXS vacuum chamber is mounted on two perpendicular motorized stages from Physik Instrumente (PI), with travel ranges of $52 \mathrm{~mm}$ along the laser-beam direction and $102 \mathrm{~mm}$ transverse to the laser beam, a minimum incremental motion of $0.5 \mu \mathrm{m}$ and unidirectional repeatability of (a)

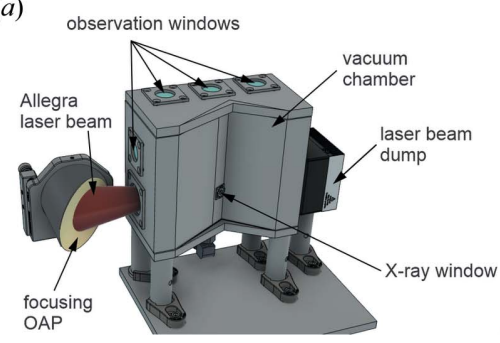

(b)

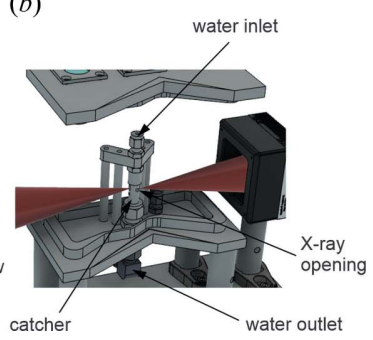

Figure 2

Schematic diagrams of water-jet PXS optimized for the high-performance L1 Allegra laser. Water is continuously recycled in a closed-loop pumping system with inlet and outlet reservoirs (not shown in the scheme). The water jet is shaped by a nozzle in the water inlet area and driven by a pressure difference. 
$0.5 \mu \mathrm{m}$. The OAP is optimized to generate the brightest spark at a low laser pulse energy in the focus in air after removing the chamber from the beam path. After initial placement of the chamber and coarse alignment through the observation windows, fine alignment utilizes the shape and position of the plasma plume created by the interaction of the laser with the water jet, as observed with web cameras.

The region of optimal X-ray production is defined by the rigid jet assembly and the optimally focused laser beam and has an extension of typically $<5 \mu \mathrm{m}$ perpendicular to the laserpropagation and jet-flow direction and $<50 \mu \mathrm{m}$ along the laser-propagation direction, imposing high demands on the spatial stability of the laser focus (Gustafsson, 2015; Fullagar et al., 2008). During operation, the position of the PXS is optimized using the integrated flux measured with the X-ray CCD and a RadEye detector as feedback. The RadEye detector is a large-area (position-insensitive) Geiger-Mueller counter used as a pseudo-linear detector at counting rates far below the maximum of $1 \mathrm{kHz}$, temporarily replacing a more suitable linear detector for alignment purposes.

The data presented here were collected by an Andor Newton X-ray CCD camera with an e2v CCD30-11 frontilluminated deep-depletion chip in an indirect detection mode. In this camera, the CCD is Peltier-cooled to 233 down to $223 \mathrm{~K}$ and kept in a low-pressure protective gas close behind a beryllium window. In this configuration, the $\mathrm{CCD}$ acts as a large assembly of X-ray diodes. The challenge of this configuration is that each frame can only contain a limited number of absorption events and some X-ray-generated electron clouds are only partially registered due to the reduced active space. This can, under certain circumstances, lead to spectral redistribution and charge sharing among adjacent pixels (Lutz, 2006; Bautz et al., 1999; Pavlov \& Nousek, 1999; Janesick, 2001; Fullagar et al., 2008; Uhlig, 2011).

We follow the previously published and verified procedure to calibrate, extract and correct the spectrum from the collected full-frame images (Fullagar et al., 2008; Uhlig, 2011). During the experiment, the X-ray source was operated continuously at $1 \mathrm{kHz}$ without a shutter between the source and detector. To reduce the influence of different voltage configurations in the readout and exposure mode employed by this type of CCD sensor, the exposure time was chosen as $2 \mathrm{~s}$ per frame. For the regular operation of such a characterization method, a camera shutter, a laser pulse shutter or a frame storage/transfer approach on a larger chip could be employed to allow for significantly shorter exposure times and subsequent faster spectral feedback.

Each absorption event results in a de-excitation charge cascade, creating a charge cloud of characteristic value for the photon energy that is then digitized to a number. In the current configuration and in the absence of partial registry, typically one analogue-to-digital (AD) conversion unit corresponds to $\sim 10 \mathrm{eV}$ of the initial photon energy. The measured $\mathrm{AD}$ values are then corrected by the background and calibrated by known emission lines.

The highest energy resolution is achieved by suppressing events that are spectrally redistributed, which is often achieved by suppressing absorption events that extend beyond a single pixel (Fullagar et al., 2008; Uhlig, 2011). The frontilluminated $\mathrm{e} 2 \mathrm{v}$ sensor used in this experiment has an approximate depletion depth of $40 \mu \mathrm{m}$ (determined by modelling the observed response function) which, in combination with the large pixel size, leads to a small fraction of redistributed events. The total intensity of the measured spectrum is then deduced by normalizing the observed event histogram to the expected quantum efficiency of the deep depletion layer at each energy. For this experiment, the difference between the number of events observed in a single pixel and the total number of events observed in any number of pixels is usually kept below $5 \%$, or $20 \%$ if each exposed pixel is counted as a separate event, supporting this approach. The challenge of this approach is a significantly limited maximum number of absorption events (typically 1/200 pixel) recorded by the camera.

For the analysis, we have implemented the following procedure. For each pixel, an individual background level is subtracted using the statistics over 800 frames to account for spatial temperature differences due to cooling gradients over the chip area. Then a common background level for each frame is determined and subtracted to account for background variations over the progression of the frames due to temperature variations induced by the continuous exposure to $\mathrm{X}$-ray radiation and readout. A threshold is applied to the data corresponding to five times the $\sigma$ of the background model (assuming a Gaussian distribution). Histograms of the analogue-to-digital conversion (ADC) steps are then created for all pixels and for the absorption events contained within a single spatially isolated CCD pixel (Fullagar et al., 2008; Uhlig, 2011). The ADC units in the histogram are then converted into energy units by aligning the (fitted) peak of the measured $K_{\alpha}$ emission of an iron calibration foil to $6405.2 \mathrm{eV}$. The observed intensity is then converted into a photon flux accounting for accumulation time, laser repetition rate and the solid angle of the detection setup. Finally, the number of detected photons is corrected by the detection probability for the corresponding setup. This probability includes the absorption probabilities of all materials in the beam path, from the source to the detector for the absorption measurement (with the exception of the sample) or from the sample to the detector for the emission measurement, and in both cases the quantum efficiency of the detector. These energy-dependent correction factors used database values from the xraylib (Schoonjans et al., 2011) broadened by a Gaussian kernel to represent the CCD's inferred X-ray energy resolution. The integrated flux of the X-ray source is sufficiently strong that spatial constraints in the X-ray hutch necessitate accumulation with a (copper) filter in the direct detection method [X-ray absorption spectroscopy (XAS)] that is then compensated as part of the data analysis. The effective removal of the $\mathrm{Cu} \mathrm{K}$ absorption edge (without optimization of the $\mathrm{Cu}$ thickness parameter) increases the trust in our compensation procedure.

These commissioning experiments were performed to characterize the performance and demonstrate the generic suitability of this laser-based X-ray spectroscopic setup for 

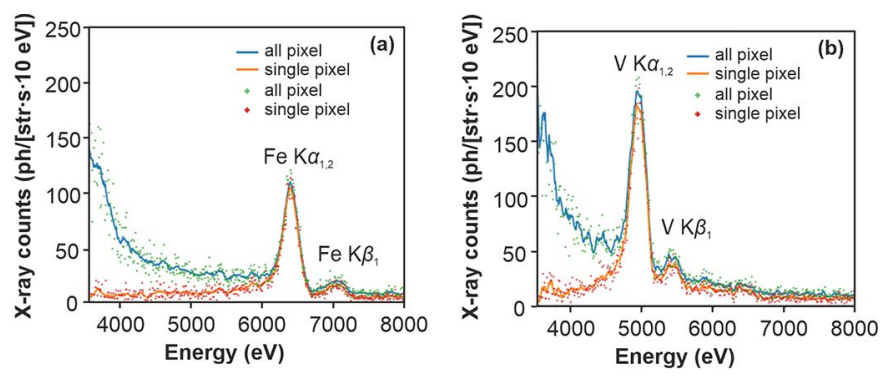

Figure 3

X-ray emission spectra of $(a)$ iron and $(b)$ vanadium acquired using EXAFS Materials calibration foils. (The thicknesses of the foils are $7.5 \mu \mathrm{m}$ for $\mathrm{Fe}$ and $5 \mu \mathrm{m}$ for V.)

pump-probe experiments. The long path in air and the copper foil place a severe limitation on the usable spectral range shown in Fig. 3(a). Future experiments with a focus on analysis of the laser-plasma interaction should employ alternative methods to limit the X-ray flux on the detector (see above) and replace the air in the beam path with e.g. helium to extend the accessible spectral range.

\subsection{Characterization of this source for $X$-ray emission spectroscopy}

A metal foil from EXAFS Materials was placed close to the $\mathrm{X}$-ray window as an initial target. The illuminated area was a round spot of $2 \mathrm{~mm}$ defined by an aperture at a total distance of $\sim 42 \mathrm{~mm}$ from the source. This distance was limited by the geometry of the target chamber (Fig. 2) (the closest position after the window/aperture would be $\sim 18 \mathrm{~mm}$ from the source). The induced X-ray fluorescence emission was collected on the CCD at a distance of $210 \mathrm{~mm}$ from the foil and at an angle of approximately $90^{\circ}$ to the incident $\mathrm{X}$-ray beam. This position is close to the typical placement of a bent von Hamos type analyser crystal using $\mathrm{Si}$ for $\mathrm{Cu} K_{\alpha} \mathrm{X}$-ray emission spectroscopy (XES) observations (Szlachetko et al., 2012), one of the analyser geometries planned for the setup. For each spectrum we collected 800 images in two sets, maintaining the general camera settings and alignment. The resulting XES spectra were extracted using the method described above and are shown in Fig. 3. The observed flux is binned into $10 \mathrm{eV}$ bins to represent the approximate width that would be used for high-resolution XES measurements (typically 10-40 eV). The expected Fano width of $\sim 110 \mathrm{eV}$ was convolved with the baseline width (from the background) and is approximately the resolution observed in the CCD data.

\subsection{Characterization of the direct flux and X-ray absorption spectrum}

The camera was placed at a distance of $915 \mathrm{~mm}$ in the line of sight of the X-ray window for direct X-ray detection, through air. The absorption sample was placed close to the source, to avoid the influence of fluorescence photons, and potential sources of secondary radiation were carefully removed from the beam path. The exposure time and camera distance were chosen to allow for collection of the radiation while main-
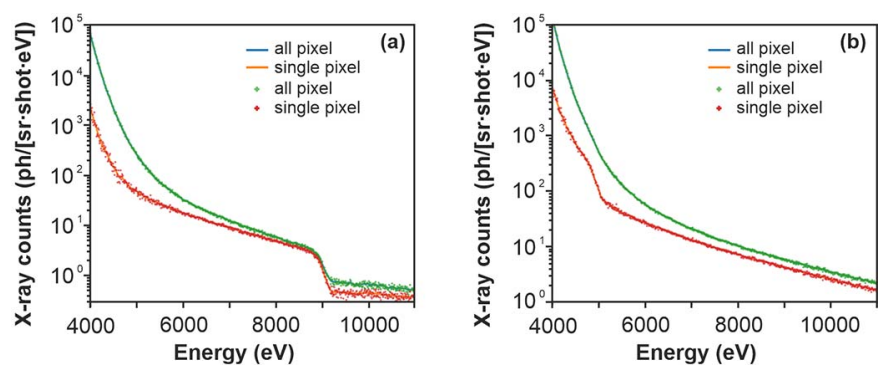

Figure 4

Direct CCD observed X-ray absorption spectra of $(a)$ copper and $(b)$ titanium acquired using EXAFS Materials calibration foils. The thicknesses of the foils are $7.5 \mu \mathrm{m}$ for $\mathrm{Cu}$ and $6 \mu \mathrm{m}$ for Ti. The shown flux is compensated for solid angle and all materials between source and detector except for the foils themselves.

taining a sufficiently low number of exposed pixels to use the camera as a direct detector. In each experiment, we collected 800 images in two sets, while the camera parameters and alignment were kept unchanged. The spectra in Fig. 4 clearly show the ability of the source to provide a sufficient number of photons to accumulate X-ray absorption spectra over a wide range of energies. The low-energy limit of these spectra is defined through the absorption of air that at $91 \mathrm{~cm}$ and $4 \mathrm{keV}$ transmits only $0.01 \%$ of all X-rays.

\subsection{Discussion of average and peak flux}

The experiment in this paper describes the first use of the L1 Allegra laser to drive a water-jet PXS and, to the best of our knowledge, the first reported use of such a high-power $1 \mathrm{kHz}$ OPCPA laser system to drive this type of X-ray source for the creation of broadband radiation. The emission and absorption spectra in Figs. 3 and 4 were accumulated over an effective time of $2 \times 13 \mathrm{~min}$, in the case of XAS limited mainly by the speed of the camera. If the spectra are also compensated for the sample foil, we can estimate the achieved flux to be 260 photons per shot $\mathrm{sr}^{-1} \mathrm{eV}^{-1}$ at $6 \mathrm{keV}$ (corresponding to $1.5 \times 10^{6} \mathrm{ph} \mathrm{sr}^{-1} \mathrm{~s}^{-1}$ per $0.1 \% \mathrm{BW}$ ) during a subset of the frame from $100 \mathrm{~s}$. This is not far from the expected value for the combination of laser power and source conditions used here if we use prior experiments as reference (Miaja-Avila et al., 2015; Uhlig et al., 2013). Visible drifts of the laser beam during the accumulation period significantly reduced the flux over the progression of frames (which was the reason for the changing background levels). Actively (manually) following these movements through small steps in the $2-5 \mu \mathrm{m}$ range using the motorized stages, and the integral X-ray flux as a monitor, enabled us to maintain the observed peak flux over a longer period. While the inclusion of an active feedback system would be a viable option, it is hoped that the currently introduced active beam stabilization will remove this need.

Fig. 5 shows the spectrum for the maximum flux reached shortly after one such adjustment. The integrated flux is 3.5 times higher than the average output used for accumulation of the spectra in Figs. 3 and 4. This factor is an estimation gained from the integral flux observed on the CCD camera. Previous studies (Fullagar, Uhlig et al., 2007; Fullagar et al., 2008; Miaja- 


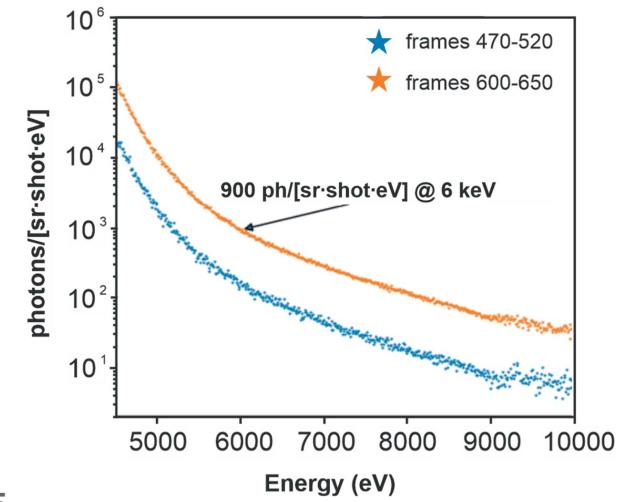

Figure 5

Energy (eV)

Two selected sets of data, each containing 50 frames, clearly demonstrating the achieved photon flux (orange) and the effect of driving laser instabilities (blue). A flux of $900 \mathrm{ph} \mathrm{sr}^{-1}$ shot $^{-1} \mathrm{eV}^{-1}$ at $6 \mathrm{keV}$ (corresponding to $5.4 \times 10^{6} \mathrm{ph} \mathrm{sr}^{-1} \mathrm{~s}^{-1}$ per $0.1 \% \mathrm{BW}$ at $6 \mathrm{keV}$ ) was observed after source optimization.

Avila et al., 2015) indicate that the conditions at the interaction point influence the electron temperature, and with it not only the total emitted flux but also the emitted spectrum. Under the conditions in this experiment, we preferentially record photons with higher photon energy $(>8 \mathrm{keV})$. The electron temperature, and with it the fraction of emitted high-energy photons, is reduced if the focal conditions are worse, which is why we feel comfortable using this factor as an estimate for the flux at $6 \mathrm{keV}$. Factoring in this effect the achieved peak emission is $>900$ photons per shot $\mathrm{sr}^{-1} \mathrm{eV}^{-1}$ at $6 \mathrm{keV}$ (corresponding to $5.4 \times 10^{6} \mathrm{ph} \mathrm{sr}^{-1} \mathrm{~s}^{-1}$ per $0.1 \% \mathrm{BW}$ at $\left.6 \mathrm{keV}\right)$.

For the experiment presented here, 10 to $12 \mathrm{~mJ}$ were used to drive the water-jet PXS. The L1 Allegra laser is under rapid development and has recently demonstrated an ability to reach a pulse energy of $>50 \mathrm{~mJ}$ (at the laser output). It is designed to reach $100 \mathrm{~mJ}$ (Batysta et al., 2016) with discussions currently underway for further increase. It may be anticipated that operating the water-jet PXS at increased pulse energy will also result in increased X-ray flux. Currently, an upgrade of the water-jet PXS vacuum system is being implemented that will improve the vacuum conditions, which have shown to be critical for reducing self-phase modulation and thus the achievable maximum laser fluence (Thoss, 2003; Mourou et al., 2006). The effects of an upgraded vacuum system and an improved laser focus through the reduction of the current astigmatism are difficult to predict. However, the implementation of active and passive beam stabilization and, if still necessary, the use of an active feedback system for the target position will stabilize the already measured 3.5-fold flux increase. If we estimate the increased X-ray flux through the ten-fold higher laser power and the other updates with a very conservative factor of 4 , after implementation of multiaspectual upgrades we can expect at least a 14-fold increase in flux to $>3600$ photons per shot $\mathrm{sr}^{-1} \mathrm{eV}^{-1}$ at $6 \mathrm{keV}$ (corresponding to $2.2 \times 10^{7} \mathrm{ph} \mathrm{sr}^{-1} \mathrm{~s}^{-1}$ per $0.1 \% \mathrm{BW}$ ) together with a raised electron temperature.

Very recent work from the Elsaesser group used an OPCPA as a driving laser with $5 \mu \mathrm{m}$ wavelength and created an X-ray source with copper tape for generation of $\mathrm{Cu} \mathrm{K \alpha}$ emission.
They achieved in comparable units $9.5 \times 10^{9} \mathrm{ph} \mathrm{sr}^{-1} \mathrm{~s}^{-1}$ using the superior generation of hot electrons at a longer laser wavelength (Koç et al., 2021). Based on our numbers and assuming an active bandwidth of $>1 \mathrm{keV}$ for generation of the core hole in the hard X-ray range (e.g. iron), we can expect an X-ray emission flux on the same scale from our water-jet target.

Based on the observed numbers and reasonable improvements, we can estimate the conditions for experiments performed with this source. For a cylindrically bent crystal in von Hamos geometry with a $25 \mathrm{~cm}$ focal distance under normal incidence, we can assume for the $1 \mathrm{eV}$ energetic acceptance a $12 \mu \mathrm{m}$ wide acceptance stripe in the dispersive direction, which corresponds to a solid angle of $20 \mu \mathrm{sr}$. With a crystal size of $10 \mathrm{~cm}$ in the non-dispersion direction, we can expect approximately $17 \mathrm{ph} \mathrm{s}^{-1} \mathrm{eV}^{-1}$ at $6 \mathrm{keV}$ on the detector, not including losses due to air absorption and reflectivity efficiency. As the source is broadband and the full spectral window is collected simultaneously, the full spectrum is accumulated at a comparable rate. For a differential spectrum $10^{5}$ photons per energy bin can be sufficient, assuming $1 \%$ fluctuation of the pump laser as the main source of noise. This corresponds to an expected accumulation time of approximately $>2 \mathrm{~h}$ for a full transient spectrum in the range of the iron $K$ edge, which is reduced to $<10 \mathrm{~min}$ after the planned improvements. Similarly, at the observed maximum flux for iron foil emission, a rough estimate yields $1 \mathrm{ph} \mathrm{s}^{-1}$ on the detector over the full spectrum when collecting nearly background-free emission spectra $\left(K_{\alpha}\right)$. A usable spectrum can be achieved with 6000 photons ( $2 \mathrm{~h}$ accumulation time) reduced to $<10 \mathrm{~min}$ at the conservatively improved conditions. The often targeted transition metal $K_{\beta}$ lines have a 20-fold lower emission probability and will only be accessible after the improvements.

Further reductions in the accumulation time in X-ray spectroscopy experiments could also be pursued based on adaptations of the spectrometer design. The beam path of XAS measurements is limited by the opening angle of the experiment and thus cannot be significantly increased. In contrast, the recently deployed multiple crystal detection schemes (Alonso-Mori et al., 2012; Kalinko et al., 2020) would allow a six-fold decrease in the accumulation time. Other developments, such as the use of energy-dispersive cryogenic detectors, could reduce the accumulation times even more (Doriese et al., 2017; O'Neil et al., 2017; Uhlig et al., 2015; Miaja-Avila et al., 2016). Low-temperature detectors, such as microcalorimeters, analyse the energy of individual photons without the use of optical elements and found their first use in the field of ultra-fast spectroscopy together with an earlier generation of the water-jet PXS (Fullagar et al., 2008; Uhlig et al., 2013; Uhlig, 2011).

\section{Summary and outlook}

In summary, we have shown that at this early stage the L1 Allegra laser combined with a water-jet PXS can deliver sufficient X-ray flux to perform proof-of-principle experi- 
ments in X-ray emission and absorption spectroscopies, and we have outlined a pathway that will transform water-jet PXS within the ELI Beamlines X-ray spectroscopy end-station to become a valuable user facility for time-resolved pump-probe studies.

\section{Acknowledgements}

We thank R. Lera and D.-D. Mai for helping with beam transport organization. We express our gratitude to A. Wolf and Z. Svoboda for technical support. We also thank the L1 Allegra laser team for laser development and support during the beamtime. We would also like to thank the reviewer, who has, with their exceptionally profound review, helped improve the paper.

\section{Funding information}

This work was partially supported by the European Regional Development Fund (Adonis) (grant No. CZ.02.1.01/0.0/0.0/ 16_019/0000789). J. Uhlig acknowledges funding from the Vetenskapsrådet under the number 2020-04995.

\section{References}

Afshari, M., Krumey, P., Menn, D., Nicoul, M., Brinks, F., Tarasevitch, A. \& Sokolowski-Tinten, K. (2020). Struct. Dyn. 7, 014301.

Alonso-Mori, R., Kern, J., Sokaras, D., Weng, T.-C., Nordlund, D., Tran, R., Montanez, P., Delor, J., Yachandra, V. K., Yano, J. \& Bergmann, U. (2012). Rev. Sci. Instrum. 83, 073114.

Andrikopoulos, P. C., Liu, Y., Picchiotti, A., Lenngren, N., Kloz, M., Chaudhari, A. S., Precek, M., Rebarz, M., Andreasson, J., Hajdu, J., Schneider, B. \& Fuertes, G. (2020). Phys. Chem. Chem. Phys. 22, 6538-6552.

Antipenkov, R., Batysta, F., Boge, R., Erdman, E., Greco, M., Green, J. T., Hubka, Z., Indra, L., Majer, K., Mazanec, T., Mazůrek, P., Naylon, J., Novák, J., Šobr, V., Špaček, A., Torun, M., Tykalewicz, B., Bakule, P. \& Rus, B. (2019). OSA Tech. Dig. 2019, ATh1A. 6.

Assion, A., Baumert, T., Bergt, M., Brixner, T., Kiefer, B., Seyfried, V., Strehle, M. \& Gerber, G. (1998). Science, 282, 919-922.

Bargheer, M., Zhavoronkov, N., Woerner, M. \& Elsaesser, T. (2006). Chem. Eur. J. Chem. Phys. 7, 783-792.

Batysta, F., Antipenkov, R., Novák, J., Green, J. T., Naylon, J. A., Horáček, J., Horáček, M., Hubka, Z., Boge, R., Mazanec, T., Himmel, B., Bakule, P. \& Rus, B. (2016). Opt. Express, 24, 17843.

Bautz, M. W., Prigozhin, G. Y., Pivovaroff, M. J., Jones, S. E., Kissel, S. E. \& Ricker, G. R. (1999). Nucl. Instrum. Methods Phys. Res. A, 436, 40-52.

Benesch, F., Lee, T., Jiang, Y. \& Rose-Petruck, C. G. (2004). Opt. Lett. 29, 1030.

Brauckmann, S. K. (2017). X-ray Generation by High-Intensity Laser Pulses. PhD thesis. Heinrich-Heine-Universität Düsseldorf, Germany.

Brüggemann, B., Organero, J. A., Pascher, T., Pullerits, T. \& Yartsev, A. (2006). Phys. Rev. Lett. 97, 208301.

Brunel, F. (1987). Phys. Rev. Lett. 59, 52-55.

Chen, L. M., Zhang, J., Dong, Q. L., Teng, H., Liang, T. J., Zhao, L. Z. \& Wei, Z. Y. (2001). Phys. Plasmas, 8, 2925-2929.

Chergui, M. \& Collet, E. (2017). Chem. Rev. 117, 11025-11065.

De Roche, J., Gordon, C. M., Imrie, C. T., Ingram, M. D., Kennedy, A. R., Lo Celso, F. \& Triolo, A. (2003). Chem. Mater. 15, 3089-3097.

Dicke, B., Hoffmann, A., Stanek, J., Rampp, M. S., Grimm-Lebsanft, B., Biebl, F., Rukser, D., Maerz, B., Göries, D., Naumova, M., Biednov, M., Neuber, G., Wetzel, A., Hofmann, S. M., Roedig, P., Meents, A., Bielecki, J., Andreasson, J., Beyerlein, K. R., Chapman,
H. N., Bressler, C., Zinth, W., Rübhausen, M. \& Herres-Pawlis, S. (2018). Nat. Chem. 10, 355-362.

Doriese, W. B., Abbamonte, P., Alpert, B. K., Bennett, D. A., Denison, E. V., Fang, Y., Fischer, D. A., Fitzgerald, C. P., Fowler, J. W., Gard, J. D., Hays-Wehle, J. P., Hilton, G. C., Jaye, C., McChesney, J. L., Miaja-Avila, L., Morgan, K. M., Joe, Y. I., O’Neil, G. C., Reintsema, C. D., Rodolakis, F., Schmidt, D. R., Tatsuno, H., Uhlig, J., Vale, L. R., Ullom, J. N. \& Swetz, D. S. (2017). Rev. Sci. Instrum. 88, 053108 .

Eliezer, S. \& Kunioki, M. (2019). Applications of Laser-Plasma Interactions. Abingdon: Taylor and Francis Ltd.

Espinoza, S., Samparisi, F., Frassetto, F., Richter, S., Rebarz, M., Finke, O., Albrecht, M., Jurkovic, M., Hort, O., Fabris, N., Zymaková, A., Mai, D., Antipenkov, R., Nejdl, J., Poletto, L. \& Andreasson, J. (2020). J. Vac. Sci. Technol. B, 38, 024005.

Fullagar, W., Harbst, M., Canton, S., Uhlig, J., Walczak, M., Wahlström, C.-G. \& Sundström, V. (2007). Rev. Sci. Instrum. 78, 115105 .

Fullagar, W., Uhlig, J., Walczak, M., Canton, S. \& Sundström, V. (2008). Rev. Sci. Instrum. 79, 103302.

Fullagar, W., Uhlig, J., Walczak, M., Canton, S., Wahlström, C.-G. \& Sundström, V. (2007). New and Emerging Sources of Intense Beams of Particles and Short-Wavelength Radiation. Poster. Lund: MAXlab. (https://portal.research.lu.se/files/76351387/Emerging_sources_ poster_A2_JU.pdf.)

Gibbon, P. (2005). Short Pulse Laser Interactions with Matter: An Introduction. Jülich Supercomputing Centre (JSC), Germany. Imperial College Press

Gustafsson, F. P. (2015). Investigating the Stability of a Laser-Based Plasma X-ray Source. BSc. thesis. Lund University, Sweden.

Hort, O., Albrecht, M., Finke, O., Jurkovic, M., Lera, R., Mai, D.-D., Klimesova, E., Espinoza, S., Richter, S., Gautier, J., Sebban, S., Antipenkov, R., Batysta, F., Novák, J., Green, J. T., Krikunova, M., Andreasson, J. \& Nejdl, J. (2020). Proceedings of the 3rd International Conference on Optics, Photonics and lasers (OPAL'2020), 21-23 October 2020, Tenerife, Spain, pp. 34-36.

Hort, O., Albrecht, M., Nefedova, V. E., Finke, O., Mai, D. D., Reyné, S., Giambruno, F., Frassetto, F., Poletto, L., Andreasson, J., Gautier, J., Sebban, S. \& Nejdl, J. (2019). Opt. Express, 27, 8871.

Janesick, J. R. (2001). Scientific Charge-Coupled Devices. Bellingham, Washington, USA: SPIE Press.

Kalinko, A., Caliebe, W. A., Schoch, R. \& Bauer, M. (2020). J. Synchrotron Rad. 27, 31-36.

Kjaer, K. S., Van Driel, T. B., Harlang, T. C. B., Kunnus, K., Biasin, E., Ledbetter, K., Hartsock, R. W., Reinhard, M. E., Koroidov, S., Li, L., Laursen, M. G., Hansen, F. B., Vester, P., Christensen, M., Haldrup, K., Nielsen, M. M., Dohn, A. O., Pápai, M. I., Møller, K. B., Chabera, P., Liu, Y., Tatsuno, H., Timm, C., Jarenmark, M., Uhlig, J., Sundstöm, V., Wärnmark, K., Persson, P., Németh, Z., Szemes, D. S., Bajnóczi, Vankó, G., Alonso-Mori, R., Glownia, J. M., Nelson, S., Sikorski, M., Sokaras, D., Canton, S. E., Lemke, H. T. \& Gaffney, K. J. (2019). Chem. Sci. 10, 5749-5760.

Klimesová, E., Kulyk, O., Hoque, Z., Roos, A. H., Khakurel, K., Rebarz, M., Jurkovič, M., Albrecht, M., Finke, O., Lera, R., Hort, O., Mai, D.-D., Nejdl, J., Sokol, M., Fink, R. B., Ltaief, B. L., Westphal, D., Wolf, A., Laštovička, T., Frassetto, F., Poletto, L., Andreasson, J. \& Krikunova, M. (2021). Eur. Phys. J. Spec. Top. https://doi.org/10.1140/epjs/s11734-021-00192-z.

Koç, A., Hauf, C., Woerner, M., von grafensteın, L., Ueberschaer, D., Bock, M., Griebner, U. \& Elsaesser, T. (2021). Opt. Lett. 46, 210.

Korn, G., Thoss, A., Stiel, H., Vogt, U., Richardson, M., Elsaesser, T. \& Faubel, M. (2002). Opt. Lett. 27, 866-868.

Kranz, C. \& Wächtler, M. (2021). Chem. Soc. Rev. 50, 1407-1437.

Kruer, W. L. (2003). The Physics Of Laser-Plasma Interactions. Boca Raton: CRC Press.

Kunnus, K., Vacher, M., Harlang, T. C. B., Kjaer, K. S., Haldrup, K., Biasin, E., van Driel, T. B., Pápai, M., Chabera, P., Liu, Y., Tatsuno, H., Timm, C., Källman, E., Delcey, M., Hartsock, R. W., Reinhard, 
M. E., Koroidov, S., Laursen, M. G., Hansen, F. B., Vester, P., Christensen, M., Sandberg, L., Németh, Z., Szemes, D. S., Bajnóczi, É., Alonso-Mori, R., Glownia, J. M., Nelson, S., Sikorski, M., Sokaras, D., Lemke, H. T., Canton, S. E., Møller, K. B., Nielsen, M. M., Vankó, G., Wärnmark, K., Sundström, V., Persson, P., Lundberg, M., Uhlig, J. \& Gaffney, K. J. (2020). Nat. Commun. 11, 634.

Lutz, G. (2006). J. Synchrotron Rad. 13, 99-109.

Macchi, A. (2013). A Superintense Laser-Plasma Interaction Theory Primer. Dordrecht: Springer.

Mallozzi, P. J., Epstein, H. M., Jung, R. G., Applebaum, D. C., Fairand, B. P., Gallagher, W. J., Uecker, R. L. \& Muckerheide, M. C. (1974). J. Appl. Phys. 45, 1891-1895.

Martynenko, A. S., Pikuz, S. A., Skobelev, I. Y., Ryazantsev, S. N., Baird, C. D., Booth, N., Döhl, L. N. K., Durey, P., Faenov, A. Y., Farley, D., Kodama, R., Lancaster, K., McKenna, P., Murphy, C. D., Spindloe, C., Pikuz, T. A. \& Woolsey, N. (2021). Matter Radiat. Extrem. 6, 014405.

Martynow, M., Kupfer, S., Rau, S. \& Guthmuller, J. (2019). Phys. Chem. Chem. Phys. 21, 9052-9060.

Miaja-Avila, L., O’Neil, G. C., Joe, Y. I., Alpert, B. K., Damrauer, N. H., Doriese, W. B., Fatur, S. M., Fowler, J. W., Hilton, G. C., Jimenez, R., Reintsema, C. D., Schmidt, D. R., Silverman, K. L., Swetz, D. S., Tatsuno, H. \& Ullom, J. N. (2016). Phys. Rev. X, 6, 031047.

Miaja-Avila, L., O’Neil, G. C., Uhlig, J., Cromer, C. L., Dowell, M. L., Jimenez, R., Hoover, A. S., Silverman, K. L. \& Ullom, J. N. (2015). Struct. Dyn. 2, 024301.

Milne, C. J., Penfold, T. J. \& Chergui, M. (2014). Coord. Chem. Rev. 277-278, 44-68.

Mourou, G., Tajima, T. \& Bulanov, S. (2006). Rev. Mod. Phys. 78, 309371.

Mulser, P. \& Bauer, D. (2010). High-Power Laser-Matter Interaction. Berlin, Heidelberg: Springer.

Naumova, M., Khakhulin, D., Rebarz, M., Rohrmüller, M., Dicke, B., Biednov, M., Britz, A., Espinoza, S., Grimm-Lebsanft, B., Kloz, M., Kretzschmar, N., Neuba, A., Ortmeyer, J., Schoch, R., Andreasson, J., Bauer, M., Bressler, C., Gero Schmidt, W., Henkel, G. \& Rübhausen, M. (2018). Phys. Chem. Chem. Phys. 20, 6274-6286.

Nejdl, J., Mai, D.-D., Chaulagain, U., Hort, O., Finke, O., Albrecht, M., Jurkovic, M., Lera, R., Karatodorov, S., Lamač, M., Vančura, J., Boháček, K., Espinoza, S. J., Richter, S., Rebarz, M., Klimesova, E., Krikunova, M., Kolzová, M., Antipenkov, R., Batysta, F., Novák, J., Green, J. T., Andreasson, J. \& Korn, G. (2019). Proc. SPIE, 11111, 111110I.

O’Neil, G. C., Miaja-Avila, L., Joe, Y., Alpert, B. K., Balasubramanian, M., Sagar, D. M., Doriese, W., Fowler, J. W., Fullagar, W. K., Chen, N., Hilton, G. C., Jimenez, R., Ravel, B., Reintsema, C. D.,
Schmidt, D. R., Silverman, K. L., Swetz, D. S., Uhlig, J. \& Ullom, J. N. (2017). J. Phys. Chem. Lett. 8, 1099-1104.

Otendal, M., Hemberg, O., Tuohimaa, T. T. \& Hertz, H. M. (2005). Exp. Fluids, 39, 799-804.

Pavlov, G. \& Nousek, J. (1999). Nucl. Instrum. Methods Phys. Res. A, 428, 348-366.

Pfeifer, T., Spielmann, C. \& Gerber, G. (2006). Rep. Prog. Phys. 69, 443-505.

Ponseca, C. S., Chábera, P., Uhlig, J., Persson, P. \& Sundström, V. (2017). Chem. Rev. 117, 10940-11024.

Richter, S., Rebarz, M., Herrfurth, O., Espinoza, S., Schmidt-Grund, R. \& Andreasson, J. (2021). Rev. Sci. Instrum. 92, 033104.

Schoonjans, T., Brunetti, A., Golosio, B., Sanchez del Rio, M., Solé, V. A., Ferrero, C. \& Vincze, L. (2011). At. Spectrosc. 66, 776-784.

Szlachetko, J., Nachtegaal, M., de Boni, E., Willimann, M., Safonova, O., Sa, J., Smolentsev, G., Szlachetko, M., van Bokhoven, J. A., Dousse, J. C., Hoszowska, J., Kayser, Y., Jagodzinski, P., Bergamaschi, A., Schmitt, B., David, C. \& Lücke, A. (2012). Rev. Sci. Instrum. 83, 103105.

Thoss, A. (2003). X-ray Emission and Particle Acceleration from a Liquid Jet Target Using a $1 \mathrm{kHz}$ Ultrafast Laser System. PhD thesis. Fachbereich Physik der Freien Universität Berlin, Germany.

Turcu, I. C. E. \& Dance, J. B. (1999). X-rays from Laser Plasmas: Generation and Applications. Chichester: Wiley.

Uhlig, J. (2011). Life of a Photon in X-ray Spectroscopy. PhD thesis. Lund University, Sweden.

Uhlig, J., Doriese, W. B., Fowler, J. W., Swetz, D. S., Jaye, C., Fischer, D. A., Reintsema, C. D., Bennett, D. A., Vale, L. R., Mandal, U., O'Neil, G. C., Miaja-Avila, L., Joe, Y. I., El Nahhas, A., Fullagar, W., Parnefjord Gustafsson, F., Sundström, V., Kurunthu, D., Hilton, G. C., Schmidt, D. R. \& Ullom, J. N. (2015). J. Synchrotron Rad. 22, 766-775.

Uhlig, J., Fullagar, W., Ullom, J. N., Doriese, W. B., Fowler, J. W., Swetz, D. S., Gador, N., Canton, S. E., Kinnunen, K., Maasilta, I. J., Reintsema, C. D., Bennett, D. A., Vale, L. R., Hilton, G. C., Irwin, K. D., Schmidt, D. R. \& Sundström, V. (2013). Phys. Rev. Lett. 110, 138302.

Uhlig, J., Wahlström, C.-G., Walczak, M., Sundström, V. \& Fullagar, W. (2011). Laser Part. Beams. 29, 415-424.

Weisshaupt, J., Juvé, V., Holtz, M., Ku, S., Woerner, M., Elsaesser, T., Ališauskas, S., Pugžlys, A. \& Baltuška, A. (2014). Nat. Photon. 8, 927-930.

Zamponi, F., Ansari, Z., Korff Schmising, C., Rothhardt, P., Zhavoronkov, N., Woerner, M., Elsaesser, T., Bargheer, M., Trobitzsch-Ryll, T. \& Haschke, M. (2009). Appl. Phys. A, 96, 51-58.

Zymaková, A., Prasad, K. K., Picchiotti, A., Błachucki, W., Szlachetko, J., Rebarz, M., Uhlig, J. \& Andreasson, J. (2020). J. Synchrotron Rad. 27, 1730-1733. 